
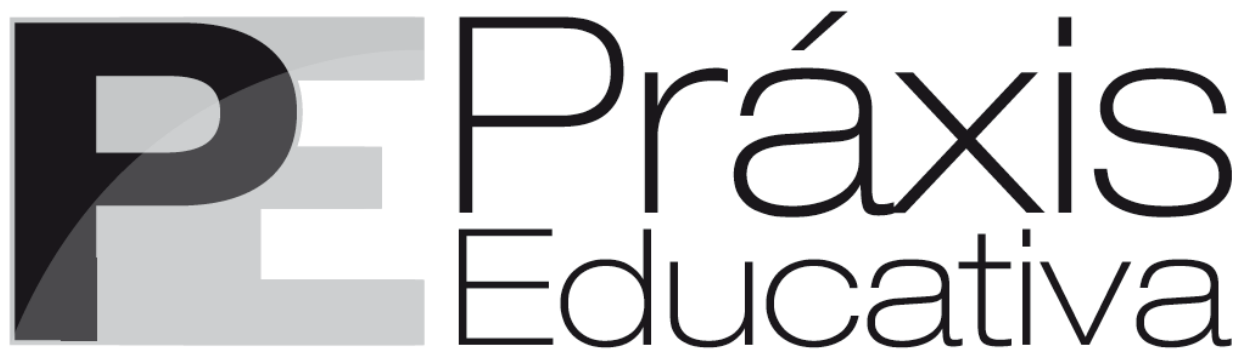

ISSN 1809-4031

elSSN 1809-4309

https://doi.org/10.5212/PraxEduc.v.15.13790.037

\title{
A elaboração de Planos Municipais na perspectiva da análise institucional e da abordagem do ciclo de políticas
}

\section{The elaboration of Municipal Plans from the perspective of institutional analysis and policy cycle approach}

\section{La elaboración de Planes Municipales desde la perspectiva del análisis institucional y abordaje del ciclo de políticas}

\author{
Tatiane Oliveira Santos Nascimento* \\ iD https://orcid.org/0000-0001-5724-0732 \\ Maria Eliza Nogueira Oliveira* \\ iD https://orcid.org/0000-0002-1771-1488 \\ Cristiano Amaral Garboggini di Giorgi*** \\ iD https:/ / orcid.org/0000-0002-3977-3217
}

Resumo: Neste artigo, analisa-se o processo de elaboração dos Planos Municipais de Educação de dois municípios paulistas na perspectiva teórico-metodológica da análise institucional e da abordagem do ciclo de políticas. Buscou-se compreender como os sujeitos direcionaram suas ações e conduziram os trabalhos de elaboração dos planos diante do desafio de atender às normas nacionais sem prejuízo das demandas locais. Constatou-se que, em ambos os municípios, os sujeitos seguiram as normas oficiais da esfera Federal, conferindo legitimidade ao processo e, ao mesmo tempo, adotaram estratégias arbitrárias de adequação do texto político ao contexto de seus referidos sistemas. Concluiu-se que o poder instituído pode atuar no sentido de motivar práticas voltadas a novos modos de se fazer política assim como fortalecer o uso de estratégias que reforçam o centralismo histórico no campo da política educacional.

Palavras-chave: Planos Municipais de Educação. Análise Institucional. Abordagem do ciclo de políticas.

\footnotetext{
* Mestre em Educação pela Universidade do Oeste Paulista (UNOESTE/Presidente Prudente). Bolsista Coordenação de Aperfeiçoamento de Pessoal de Nível Superior - CAPES (2016-2017). E-mail: <tati_88@hotmail.com>.

** Doutora em Educação pela Universidade Estadual Paulista (UNESP/ Marília) e docente do Mestrado em Educação (UNOESTE/Presidente Prudente).E-mail: <mariaeliza_oliveira@yahoo.com.br>.

*** Professor Titular aposentado da Universidade Estadual Paulista (UNESP/Presidente Prudente - SP) e docente do Mestrado em Educação (UNOESTE/Presidente Prudente). E-mail: <utopico92@gmail.com>.
} 


\begin{abstract}
In this paper, the process of elaborating the Municipal Education Plans of two municipalities of São Paulo, Brazil, is analyzed based on the theoretical-methodological perspective of the institutional analysis and the policy cycle approach. It was sought to understand how the subjects directed their actions and carried out the work of elaborating the plans faced with the challenge of meeting national standards without harming local demands. It was verified that, in both municipalities, the subjects followed the official norms of the Federal sphere, giving legitimacy to the process, and, at the same time, they adopted arbitrary strategies of adequacy of the policy text to the context of its systems. It was concluded that the instituted power can act to motivate practices aimed at new ways of doing policies as well as strengthening the use of strategies that reinforce historical centralism in the field of education policy.
\end{abstract}

Keywords: Municipal Education Plans. Institutional Analysis. Policy cycle approach.

Resumen: En este artículo, se analiza el proceso de elaboración de los Planes Municipales de Educación de dos municipios de São Paulo en la perspectiva teórico-metodológicas del análisis institucional y el abordaje del ciclo de políticas. Se buscó entender cómo los sujetos dirigieron sus acciones y llevaron a cabo los trabajos de elaboración de los planes frente al desafío de cumplir con las normas nacionales sin perjudicar las demandas locales. Se verificó que, en ambos municipios, los sujetos siguieron las normas oficiales de la esfera Federal, dando legitimidad al proceso, y, al mismo tiempo, adoptaron estrategias arbitrarias de adecuación del texto político al contexto de sus referidos sistemas. Se concluyó que el poder instituido puede actuar en el sentido de motivar prácticas dedicadas a nuevos modos de hacer política, así como fortalecer el uso de estrategias que refuerzan el centralismo histórico en el ámbito de la política educativa.

Palabras clave: Planes Municipales de Educación. Análisis Institucional. Abordaje del ciclo de las políticas.

\title{
Introdução
}

O Plano Nacional de Educação (PNE), aprovado pela Lei No 10.172, de 9 de janeiro de 2001, determinou, em seu artigo $2^{\circ}$, a elaboração de planos decenais, com base no documento nacional, a todos os entes federados. Mantida essa exigência no plano atual (Lei No 13.005, de 25 de junho de 2014), delimitou-se, aos estados e aos municípios, o prazo de um ano, a partir da data de publicação da referida lei, para o cumprimento dessa determinação especificada no artigo $8^{\circ}$. Diante dessa disposição, o Conselho Nacional dos Secretários de Educação (CONSED) e a União dos Dirigentes Municipais de Educação (UNDIME), em parceria com o Ministério da Educação (MEC), formaram uma rede de assistência técnica para auxiliar os estados, o Distrito Federal e os municípios na elaboração dos planos subnacionais, claramente fundamentada em uma concepção sistêmica de gestão educacional, cujos interesses se articulam em torno de objetivos compartilhados.

Com relação ao delineamento das metas do PNE, destacamos a influência significativa da Conferência Nacional de Educação (CONAE - 2010) no cenário educacional brasileiro - articulada em torno da temática "Construindo um Sistema Nacional Articulado de Educação: Plano Nacional de Educação, suas diretrizes e estratégias de ação" -, como espaço primordial de diálogo entre representantes de diversas organizações sociais, públicas e privadas ${ }^{1}$, com o objetivo de atender às particularidades locais resultantes das diversidades culturais e regionais e promover o debate em torno dos distintos interesses que emergem nos processos democráticos de decisão (VIEIRA, 2014; ARANDA; PERBONI; RODRIGUES, 2018). De maneira geral, os estudos consideram que a CONAE representou um importante passo na política educacional brasileira, especialmente no que diz respeito à ampliação dos espaços de participação da sociedade civil organizada no delineamento de metas condizentes com as realidades regionais, posteriormente consolidadas em

\footnotetext{
${ }^{1}$ Ocorrida no período de 23 a 27 de abril de 2010, a CONAE foi precedida de Conferências Municipais, ocorridas no primeiro semestre de 2009, e de Conferências Estaduais e do Distrito Federal programadas para o segundo semestre do mesmo ano.
}

Práxis Educativa, Ponta Grossa, v. 15, e2013790, p. 1-19, 2020

Disponível em: <http://www.revistas2.uepg.br/index.php/praxiseducativa> 
planos nacionais, ampliando a visibilidade dos desafios a serem enfrentados para a garantia do direito à educação de qualidade para todos (DOURADO, 2009)

Em atendimento a uma deliberação da CONAE (2010), instituiu-se, em 2011, a Secretaria de Articulação com os Sistemas de Ensino (SASE) ${ }^{2}$, cuja estrutura organizacional se formou com base em três diretorias: a Diretoria de Cooperação com os Planos de Ensino (DICOPE), responsável pelo trabalho de assessoramento aos Estados, Municípios e Distrito Federal na elaboração ou na adequação dos planos de educação; a Diretoria de Valorização dos Profissionais da Educação (DIVAPE), responsável por assessorar os processos de diagnóstico e de elaboração dos Planos de Carreira, entre outras ações de valorização dos profissionais da educação; e a Diretoria de Articulação com os Sistemas de Ensino (DASE), responsável pela consolidação do Sistema Nacional de Educação.

Para que se cumprisse a função da DICOPE, a SASE/MEC mapeou os planos decenais de estados e de municípios. Ela concluiu que, dos 27 entes federados, apenas 12 haviam elaborado seus respectivos planos de educação. Diante dessa importante constatação, a SASE/MEC organizou reuniões com o Conselho Nacional de Secretários de Educação (CONSED) e a União Nacional dos Dirigentes Municipais de Educação (UNDIME), constituindo um Comitê Tripartite que deu origem à "Rede de Assistência Técnica para a Elaboração ou Adequação dos Planos de Educação", com o objetivo de transpor as fronteiras entre o MEC e as entidades subnacionais e trabalhar para que os planos de educação fossem sancionados em sua totalidade.

A composição da Rede deu-se por meio da indicação de Avaliadores Educacionais (AE), coordenada pela UNDIME e o CONSED, em cada unidade federada, tendo como parâmetro o perfil profissional para o exercício de funções técnicas (AE Técnicos), executoras (Coordenadores Estaduais) e supervisoras (AE Supervisores e Supervisores Gerais). Por influência da exigência legal, a Rede foi sendo ampliada progressivamente, reunindo, em 2014, mais de 300 AE distribuídos por todo o país.

Por meio do Sistema Integrado de Monitoramento Execução e Controle (SASE/SIMEC), as etapas de elaboração dos planos foram acompanhadas de forma sistemática pelos gestores, visando à garantia de aprovação dos planos no prazo especificado em lei. Com relação às orientações, contando com o apoio de diversas entidades, organizações e pesquisadores da Universidade Federal de Pernambuco (UFPE) e da Associação Nacional de Política e Administração da Educação (ANPAE), a SASE/MEC elaborou um conjunto de quatro documentos $^{3}$, sendo um documento de base, um documento de orientação para a elaboração ou adequação dos planos de educação; um documento com sugestões de metas para cada estado e município, considerando-se o diagnóstico inicial e as possibilidades de avanço; e um quarto documento apresentando a importância de cada uma das metas nacionais. Esses materiais subsidiaram as redes municipais no processo de elaboração de seus planos educacionais e, em nossa pesquisa, foram selecionados constituindo parte de nossos objetos de análise.

Da análise do referido material, evidenciamos a prevalência de discursos que reafirmam a adoção do paradigma da gestão democrática como referência predominante no processo de elaboração dos planos. Todavia, consideramos a possibilidade dessa participação não ter produzido efeitos para além das mudanças substanciais na condução da elaboração do texto, permanecendo

\footnotetext{
2 A SASE foi criada a partir do Decreto $N^{\circ} 7.480$, de 16 de maio de 2011, e reestruturada após a publicação do Decreto $\mathrm{n}^{\mathrm{o}} 7.690$, de 2 de março de 2012.

3 Os Cadernos de Orientações foram acessados por meio do portal eletrônico do Ministério da Educação $<$ http://pne.mec.gov.br/monitorando-e-avaliando/caderno-de-orientacoes-para-monitoramento $>$. Acesso em: 20 out. 2018.
} 
ausentes normas voltadas à orientação e à garantia da efetivação do regime de colaboração, que compreendemos ser a condição necessária para o cumprimento das metas do plano decenal.

Dessa maneira, procuramos analisar como as orientações se refletiram na elaboração dos Planos Municipais de dois municípios do interior paulista por meio de um conjunto de entrevistas realizadas com os principais agentes da elaboração. As entrevistas foram orientadas por questões que nos permitiram identificar os maiores impasses vivenciados e as estratégias por eles utilizadas no processo.

Partimos do pressuposto de que as políticas educacionais formuladas no âmbito do Estado passam por significativas mudanças no contexto da prática composto por um conjunto de sujeitos capazes de transformar o conteúdo do texto político em ações que atendam a novas demandas impostas pelas relações cotidianas e por uma soma de interesses que podem se converter em processos de resistência ao instituído.

Assim, elaboramos o presente artigo que está dividido em duas seções. Na primeira, apresentamos os pressupostos fundamentais da corrente institucionalista - assumida pelos autores como posicionamento epistemológico norteador das análises - e os elementos basilares da abordagem do Ciclo de políticas desenvolvida por Stephen Ball e colaboradores e apresentada como recurso teórico-analítico aos estudos em política educacional (MAINARDES, 2006, 2018) ${ }^{4}$. Nosso objetivo é ensaiar possíveis aproximações entre as duas abordagens, de modo a ampliar o escopo teórico dos estudos que analisam as políticas em seu processo de implementação a partir da ação dos sujeitos. Na segunda seção, analisamos os dados da pesquisa, com apoio de nosso referencial, com o intuito de indicar os principais elementos norteadores desse processo.

\section{O movimento institucionalista e a abordagem do Ciclo de políticas: possíveis aproximações}

Inaugurado na sociedade francesa, na década de 1960, o movimento institucionalista emergiu com o objetivo de "[...] propiciar, apoiar e deflagrar nas comunidades, nos coletivos e conjuntos de pessoas processos de autoanálise e de autogestão" (BAREMBLITT, 1994, p. 14). Conquanto tenha sido um movimento que visou à condução de processos de intervenção, organizados pelos próprios analistas, por meio dos quais fosse possível não apenas mapear os saberes produzidos no âmbito institucional, mas também promover diálogos e reflexões que permitissem aos sujeitos situar, rever e transformar suas práticas, as ferramentas conceituais produzidas nesse campo podem auxiliar os pesquisadores em suas análises acerca dos processos democráticos voltados ao delineamento de políticas públicas, justamente por serem eles propulsores de momentos de autoanálise que permitem aos coletivos se organizarem em torno de novos projetos em um processo instituinte. Tendo em vista esse objetivo, o movimento institucionalista sugere a revisão da função do analista e dos pesquisadores, antes considerados experts comunicadores da verdade produzida no campo científico, situando-os na posição daquele que busca apreender os saberes construídos na esfera cotidiana.

Gregorio Franklin Baremblitt (1994), em seu célebre "Compêndio de Análise Institucional", considera que, ao subordinar os saberes dos membros de uma comunidade ao saber dos experts, reforça-se o controle externo sobre as condições de vida dos indivíduos, tornando-os

\footnotetext{
${ }^{4}$ A respeito da abordagem do Ciclo de políticas, ver também: Hojas (2019), Hostins e Rochadel (2019), Lima, Souza e Luce (2018), Mainardes e Gandin (2013a, 2013b), Mainardes e Marcondes (2009), Mainardes e Stremel (2015), Pavezi (2018), Rosa (2019), Sousa (2018), entre outros.
}

Práxis Educativa, Ponta Grossa, v. 15, e2013790, p. 1-19, 2020 Disponível em: <http://www.revistas2.uepg.br/index.php/praxiseducativa> 
dependentes dos organismos de Estado e/ou empresariais, incapazes, portanto, de gerir sua própria existência. Desse modo, com o objetivo de dar um novo sentido à atividade científica, atribuindo a ela um sentido político e prático, os analistas institucionais são convocados a submeter suas teorias, seus métodos e suas técnicas a uma crítica profunda, "[...] que os faça separar, dentro dos organismos aos quais pertencem, o que é produto de sua origem, de sua pertença ao bloco dominante das forças sociais e o que pode ser útil a uma autoanálise, a uma autogestão, da qual os segmentos dominados e explorados sejam protagonistas" (BAREMBLITT, 1994, p. 18). As considerações do autor remetem-nos à revisão realizada por Michel Foucault acerca da função do intelectual:

\begin{abstract}
Ora, o que os intelectuais descobriram recentemente é que as massas não necessitam deles para saber; elas sabem perfeitamente, claramente, muito melhor do que eles; e elas o dizem muito bem. Mas existe um sistema de poder que barra, proíbe, invalida esse discurso e esse saber. Poder que não se encontra somente nas instâncias superiores da censura, mas que penetra muito profundamente, muito sutilmente em toda a trama da sociedade. Os próprios intelectuais fazem parte deste sistema de poder, a ideia de que eles são agentes da "consciência" e do discurso também faz parte desse sistema. O papel do intelectual não é mais o de se colocar "um pouco na frente ou um pouco de lado" para dizer a muda verdade de todos; é antes o de lutar contra as formas de poder exatamente onde ele é, ao mesmo tempo, o objeto e o instrumento: na ordem do saber, da "verdade", da "consciência", do discurso. (FOUCAULT, 1979, p. 71).
\end{abstract}

Ao assumirmos um posicionamento epistemológico ancorado na corrente institucionalista, situamos as diretrizes educacionais no plano do instituído, no universo das orientações para a ação (BAREMBLITT, 1994; LIMA, 2001), em que os saberes produzidos em meio a acordos e disputas se materializam nos textos políticos, com valores objetificados, que regulam as ações dos sujeitos.

Para Baremblitt (1994, p. 30), os textos políticos, as normas, as prescrições nada mais são do que a forma material que as instituições assumem por meio de suas organizações, de seus estabelecimentos e equipamentos compreendidos como dispositivos concretos "[...] que põem em efetividade, que concretizam as opções que as instituições distribuem, que as instituições enunciam". Dessa maneira, analisar o conteúdo das diretrizes políticas é uma forma de compreender como a política vem exercendo sua função no processo de regulação das atividades humanas, restringindo e/ou potencializando as estratégias de enfrentamento ao estabelecido.

As ações transformadoras são possíveis, justamente devido à presença ativa dos sujeitos durante a implementação das políticas vigentes. Uma vez produzidas e instituídas no plano político, cabe aos agentes colocar as normas em prática, operando transformações no âmbito da realidade social. A esses processos de transformação, Baremblitt (1994) denomina de instituintes ou de forças instituintes capazes de produzir novos códigos, novos instituídos; são, por isso mesmo, forças que podem ser concebidas como forças transformadoras, produtoras de novas realidades.

Para o autor, tanto as forças transformadoras como as forças reprodutoras da estrutura social atuam em um mesmo plano, em conjunto. Assim, organizações e estabelecimentos intervém na sociedade tanto como agentes reprodutores de uma determinada ordem social - por meio de um saber legitimado, que imprime um determinado sentido às ações - quanto agentes de transgressão, quando os sujeitos atribuem novos sentidos às suas próprias ações, criando novos saberes que se articulam, conferindo novas funcionalidades a esses mesmos estabelecimentos que passam a ser reconhecidos também por sua força transformadora. Esse movimento, denominado de transversalidade, é que define a "concepção institucionalista" da sociedade.

A interpenetração a nível instituinte, produtivo, chama-se transversalidade, que se define também como uma dimensão da vida social e organizacional que não se reduz à ordem hierárquica da verticalidade nem à ordem informal da horizontalidade. Os efeitos da

Práxis Educativa, Ponta Grossa, v. 15, e2013790, p. 1-19, 2020

Disponível em: <http://www.revistas2.uepg.br/index.php/praxiseducativa> 
transversalidade caracterizam-se por criar dispositivos que não respeitam os limites das unidades organizacionais formalmente constituídas, gerando assim movimentos e montagens alternativos, marginais e até clandestinos às estruturas oficiais e consagradas. (BAREMBLITT, 1994, p. 38).

Nesse sentido, consideramos pertinente pautar nossas análises em abordagens que valorizem os processos instituintes, que ultrapassam os limites organizacionais e que sejam capazes de captar os "[...] movimentos e montagens alternativos, marginais e até clandestinos às estruturas oficiais e consagradas" (BAREMBLITT, 1994, p. 38). Nessa busca, deparamo-nos com a abordagem do Ciclo de políticas, cujos elementos constituintes perpassam a valorização de diferentes contextos tais como os contextos "da influência", "da produção do texto" e "da prática", estabelecendo um diálogo profícuo com os pressupostos institucionalistas ao evidenciar os aspectos micropolíticos, dando visibilidade não apenas à produção dos saberes instituídos que orientam as políticas oficiais, mas aos saberes instituintes, que escapam aos limites impostos pelas organizações formais, abrindo espaços para a emergência de novos saberes e novas práticas.

Análises orientadas pelos pressupostos da abordagem do Ciclo de políticas destacam a complexidade da política educacional ao enfatizar "[...] os processos micropolíticos e a ação dos profissionais que lidam com as políticas no nível local e indica a necessidade de se articularem os processos macro e micro na análise de políticas educacionais" (MAINARDES, 2006, p. 49). No que diz respeito à forma de operarmos com esse instrumento em nossas análises, Mainardes (2006) destaca que não se trata de um referencial teórico-analítico estático, mas "dinâmico e flexível", permitindo ao pesquisador focar em determinados contextos.

Essa flexibilidade remete-nos ao termo enactment, empreendido por Stephen Ball e sem tradução para o português, em que os processos que compõem a política, que vão desde sua formulação à sua avaliação, não são compreendidos como momentos estanques, mas inerentes a ela. Nesses termos, o conceito de implementação, muito utilizado pelos estudiosos de políticas públicas, não se referiria a uma fase posterior à formulação, ou seja, um momento voltado à aplicação da política, como costumamos entender, mas um processo que envolve um conjunto de interações entre os grupos envolvidos que podem ou não atender aos objetivos do tex to da política. Assim, Ball (apud AVELAR, 2016, p. 6) tenta "[...] escapar dos limites da teorização modernista agradável, limpa e arrumada, focada, particularmente, em torno da noção de implementação", e considera a possibilidade de

[...] substituir isto com a noção de atuação e ver a atuação, de um lado, como um processo criativo, no qual o produto do processo de atuação é algo diferente daquilo que estava escrito no texto. Mas também, por outro lado, reconhecendo que a atuação é em parte produzida discursivamente, que as possibilidades de se pensar e falar sobre políticas são na verdade articuladas dentro dos limites de certas possibilidades discursivas. Então, ao mesmo tempo, era uma tentativa de liberar o ator político como este agente criativo na produção de políticas, mas reconhecendo que o alcance destas possibilidades criativas são, ao menos em parte, construídas em outros lugares, dentro do discurso. (AVELAR, 2016, p. 6).

É exatamente essa flexibilidade e dinamicidade - que se estendem também à metodologia proposta - fornecidas pelo instrumental teórico oferecido por Stephen Ball e colaboradores, que nos permitem articular o macro e o micro contexto de maneira muito mais eficaz do que a oferecida por modelos mais tradicionais de mesoanálise, que nos interessa neste artigo. Antes, é importante precisar que o fato de Stephen Ball enfatizar a ação dos atores não o leva a minimizar a ação estatal e, menos ainda, questionar a objetividade da realidade, negando as determinantes mais gerais das políticas, inclusive as de âmbito global.

Práxis Educativa, Ponta Grossa, v. 15, e2013790, p. 1-19, 2020 
Nesse sentido, utilizando como referência a noção de compressão do espaço-temporal de David Harvey (1989), em que o mundo globalizado se apresenta como um mundo menor, portanto mais acessível, onde os movimentos ocorrem com mais rapidez, Stephen Ball levanta a hipótese da existência de um campo "da política educacional da globalização", em que a educação aparece como condição à "participação das nações individuais dentro da economia global" em um contexto de competitividade econômica. Para o autor, é nesse contexto que os países do mundo todo assumem um discurso comum na orientação das políticas voltado à necessidade de qualificar as forças de trabalho para que os países possam competir na chamada "economia global do conhecimento". Desse movimento global, emergem as reformas educacionais conduzidas por um "conjunto bastante limitado de ideias" que, na concepção do autor, excluem e silenciam outras possibilidades de pensar a política educacional (AVELAR, 2016, p. 10).

A partir dessa realidade, que se expressa em âmbito mundial, Ball amplia seu interesse em compreender como a política se move de um espaço a outro e como o trabalho humano é exercido nessa "mobilidade política". Em outras palavras, ele busca compreender como os novos atores e espaços se articulam e relacionar o local, o nacional e a rede global, reconhecendo "[...] a interação e mobilidade das coisas, pessoas e ideias ao longo destas relações" (AVELAR, 2016, p. 10) e como a influência global redefine o papel do Estado Para isso, desenvolve alguns instrumentos analíticos que empregam conceitos como os de "rede" e "ciclos" que nos permitem conceber a política como um processo dinâmico, flexível, indeterminável e não-linear, cujos efeitos devem ser analisados e compreendidos como resultados de processos de interação que envolvem disputas travadas por diversos agentes motivados por interesses distintos.

Com apoio das abordagens teóricas brevemente apresentadas nesta seção, analisamos o processo de elaboração dos Planos Municipais a partir de dados coletados em dois municípios do interior paulista. O objetivo da pesquisa foi compreender como se deu esse processo, considerando as particularidades locais, que a abordagem do Ciclo de políticas denomina de "contexto da prática”. De modo mais específico, aproximando-nos da compreensão de Mainardes (2006, p. 50), a análise desse contexto objetiva "[...] identificar processos de resistência, acomodações, subterfúgios e conformismo dentro e entre as arenas da prática, e o delineamento de conflitos e disparidades entre os discursos nessas arenas".

\section{Breves considerações metodológicas ${ }^{5}$}

A escolha do campo de estudo resultou do levantamento e da análise de Planos Municipais de Educação (PME) de 16 municípios pertencentes a uma mesma região da UNDIME situados no interior paulista. Elegeu-se a esfera regional de atuação dessa associação, devido à forte influência por ela exercida junto a Secretarias Municipais de Educação por meio de seus Avaliadores Técnicos responsáveis pela garantia de articulação entre os planos de educação municipal, estadual e nacional, mediante trabalhos de formação, e lançamento dos planos sancionados na base do Sistema Integrado de Monitoramento, Execução e Controle do Ministério da Educação (SIMEC).

\footnotetext{
${ }^{5}$ A pesquisa foi submetida ao Comitê de Ética em Pesquisa (CEP) da Universidade do Oeste Paulista e sua execução aprovada (Plataforma Brasil/Protocolo n ${ }^{\circ}$ 3864). Em decorrência do compromisso selado por meio de documentos apresentados ao CEP, foi mantido o sigilo do nome dos municípios e dos sujeitos da pesquisa. Para cada sujeito entrevistado, foi entregue um Termo de Consentimento Livre e Esclarecido (TCLE), contendo a assinatura do pesquisador responsável pela entrevista. Posteriormente à apresentação detalhada dos objetivos e dos procedimentos, foi coletada a assinatura do participante firmando sua concordância com os termos especificados.
} 
Após o levantamento dos 16 municípios, verificou-se que apenas nove haviam inserido seus respectivos planos na Plataforma do $\mathrm{PNE}^{6}$. Concluída a análise, que envolveu processos de tabulação de dados referentes ao conteúdo dos planos, procedeu-se uma leitura comparativa em que se buscou identificar diferenças substanciais entre os documentos. Realizado esse exercício comparativo entre as metas e as estratégias dos nove Planos Municipais, comparando-os entre si em um primeiro momento e, posteriormente, com as metas e estratégias do PNE, constatou-se que apenas três planos apresentaram distinções significativas em relação aos demais planos e ao plano nacional. Foram, então, realizados contatos com as secretarias municipais desses três municípios para a realização da pesquisa empírica. Após os contatos, duas secretarias autorizaram a realização da pesquisa, cujos dados apresentaremos e discutiremos adiante.

Com relação ao percurso metodológico da pesquisa, este foi traçado a partir dos objetivos da pesquisa e de algumas questões norteadoras: Quais são os limites e as possibilidades de ação dos municípios frente às determinações do Governo Federal? De que forma os municípios utilizam de sua "autonomia" para articular e efetivar as ações propostas? Como os sistemas municipais de educação definiram suas estratégias de gestão para alcançar as metas estipuladas no PNE?

Quanto aos instrumentos de coleta de dados, foram realizadas entrevistas individuais orientadas por questões estruturantes voltadas à compreensão do processo de elaboração dos Planos Municipais, considerando as relações federativas entre a União, os Estados e os Municípios e a participação dos sujeitos no processo de elaboração dos PME em âmbito local. Com relação aos sujeitos, as questões foram direcionadas ao entendimento da maneira como eles percebem as ações políticas implícitas nessa relação, que orientam a gestão municipal no processo de execução das políticas elaboradas em esferas centralizadas. Foram também aplicados questionários abertos, com o intuito de conhecer algumas características dos sujeitos elaboradores dos PME, especialmente no que diz respeito aos aspectos referentes aos percursos formativos.

Os questionários e as entrevistas foram realizados com 12 participantes da pesquisa, sendo seis entrevistados no Município A (MA), de menor porte, e seis no Município B (MB), de maior porte $^{7}$. Os participantes foram escolhidos considerando seu nível de participação no processo.

A maior parte da coleta dos dados foi realizada no âmbito das Secretarias de Educação desses dois municípios. Todavia, alguns sujeitos da pesquisa estavam atuando em outros locais devido aos remanejamentos de cargos e de funções após o processo eleitoral. Nesses casos, as entrevistas ocorreram em locais de preferência dos entrevistados, com agendamento prévio e consentido.

No estudo, buscou-se não reduzir a pesquisa a uma descrição de seus processos de concepção e/ou execução, mas identificar os aspectos teóricos, políticos, administrativos e

\footnotetext{
${ }^{6}$ Os dados foram obtidos por meio do site do MEC, na data da pesquisa, em 8 de agosto de 2016. Ao realizar o download dos documentos, observou-se que alguns municípios inseriram na plataforma apenas a Lei sancionada, impedindo o acesso ao conteúdo total do plano.

${ }^{7}$ O Município A tem uma extensão territorial de $347,65 \mathrm{~km}^{2}$ e uma população de 23.677 habitantes, sendo $90,96 \%$ residentes em área urbana. Dentre o total de habitantes, 6.081 estão em idade escolar (zero a 19 anos de idade), representando aproximadamente $26 \%$ dessa população. A taxa de analfabetismo da população do município, de 15 anos ou mais, é $6,99 \%$, considerada uma taxa expressiva com relação ao total de habitantes. A população de 18 a 24 anos com, pelo menos, o Ensino Médio completo corresponde a 66,15\%, segundo o Censo Demográfico de 2010. O Município B, com limite territorial de $560 \mathrm{~km}^{2}$ de extensão e $16,5600 \mathrm{~km}^{2}$ em perímetro urbano, possui uma população estimada de 217.290 habitantes, aproximadamente $98 \%$ desses residentes em área urbana. A taxa de analfabetismo expressa, nesse município, com população de 15 anos de idade ou mais, é de 3,91\%. A população de 18 a 24 anos com, pelo menos, o Ensino Médio completo representa 68,17\% da população. Esses dados foram informados pelo Censo Demográfico de 2010.
}

Práxis Educativa, Ponta Grossa, v. 15, e2013790, p. 1-19, 2020 Disponível em: < http://www.revistas2.uepg.br/index.php/praxiseducativa > 
funcionais que orientaram o trabalho das equipes gestoras dos municípios para, posteriormente, realizar a análise, em busca de compreender como ocorre o movimento entre os âmbitos locais e nacional - orientados pelos pressupostos do movimento institucionalista e da abordagem do Ciclo de políticas - abstraindo, nesse percurso, elementos que ampliam o entendimento da política educacional como processo flexível e não determinado, permeado por princípios de cooperação e de colaboração entre os entes federados, como previstos constitucionalmente, mas também de disputas e de subordinação.

Respaldando-nos nas orientações dos analistas institucionais, a pesquisa adotou um viés "multirreferencial" que, nas palavras de Lapassade (1998), tem um caráter operacional, permitindo ao pesquisador identificar a convergência entre perspectivas de análise e operar com diferentes conceitos, abordagens, técnicas e instrumentos que se debruçam sobre um mesmo objeto. Dessa maneira, o conteúdo das entrevistas, integralmente transcritas, foi analisado com apoio do método clássico da análise de conteúdo de Laurence Bardin (2009), privilegiando a repetição de frequência de temas apresentados no conjunto das entrevistas. Embora, ao percorrer o nível aparente das entrevistas, o método permita identificar as regularidades, as circunstâncias, as semelhanças e o distanciamento nos discursos, em um nível mais profundo, ele identifica as fissuras que podem enriquecer o conteúdo das informações. Contemplou-se, portanto, a técnica de "decifração estrutural" (BARDIN, 2009), em que as entrevistas são analisadas não como um conjunto de falas de onde se abstraem informações únicas, mas um conjunto de discursos onde é possível decifrar as particularidades e as abstrações que nos permitem compreender o contexto de um modo mais abrangente.

A análise das entrevistas fez emergir três categorias temáticas, "elaboração", "participação" e "autonomia", que passaremos a desenvolver a seguir, buscando explorar a correlação entre elas, na medida em que fazem parte de um mesmo processo.

\section{O processo de elaboração dos Planos Municipais de Educação em dois municípios do interior paulista}

O processo de elaboração dos Planos Municipais de Educação iniciou-se em períodos anteriores à promulgação da Lei $\mathrm{N}^{\circ} 13.005 / 2014$, ainda no contexto de vigência do PNE (20012010), quando foram implementados programas e ações por parte do Governo Federal, com destaque para o Plano de Ações Articuladas (PAR/2007-2011), que estimularam a realização de diagnósticos referentes ao delineamento de metas consubstanciadas em planos educacionais, para que os Governos Federal, Estaduais e Municipais orientassem suas ações no sentido de consolidar o Sistema Nacional de Educação, em regime de colaboração, conforme previsto nos princípios constitucionais que embasam o pacto federativo.

Apesar desse importante passo, foi a partir da aprovação do novo PNE (2014-2024) que a sociedade brasileira presenciou o aprofundamento dos debates em torno da importância de aprovação desse documento, tendo em vista o elevado número de estados e de municípios que ainda não haviam promulgado seus planos decenais, colocando em risco o alcance das metas nacionais. Desde então, mediante novas prerrogativas estabelecidas pelo Ministério de Educação e o avanço eminente de programas e de políticas educacionais que vinculavam a destinação de recursos à aprovação dos planos nas esferas locais, os municípios movimentaram-se para o cumprimento da lei, temendo possíveis penalidades, especialmente as de ordem financeiras.

Dados coletados referentes ao MA revelaram que não havia nenhum plano anterior que pudesse servir como referência à equipe de elaboração do novo plano, diferentemente do MB que já havia disponibilizado uma proposta, considerando a necessidade de apenas realizar algumas 
adequações e alinhamentos ao Plano Nacional de 2014. Contudo, ao avaliar o plano, a equipe desse município constatou que a proposta estava muito distinta do documento nacional e deu início a um trabalho de elaboração de um novo PME, de acordo com as exigências do Plano Nacional.

A análise comparativa dos Planos Municipais nos dois municípios evidenciou alterações significativas em relação às 20 metas estabelecidas no PNE, demonstrando o uso de estratégias, por parte dos elaboradores, voltadas à adequação de seus respectivos planos às realidades locais. Nesse sentido, ainda que restrita, a autonomia no processo de elaboração das diretrizes foi exercida pelos sujeitos dos municípios pesquisados para que não houvesse prejuízo de garantias, firmadas por cada sistema anteriormente ao Plano Nacional, e comprometimento de parte do orçamento, considerando a ausência de metas precisas, por parte dos Governos Federal e Estadual, no que diz respeito à ampliação de recursos.

Outro dado importante se refere à ausência do Plano Estadual paulista no momento da elaboração dos Planos Municipais. Embora se tratasse de uma referência fundamental para elaboração das metas dos municípios, conforme previsto nas orientações oficiais ${ }^{8}$, a ausência desse documento foi suprida pelo documento nacional que, na ocasião, ocupou posição central como documento norteador nas discussões.

\footnotetext{
Na verdade o Plano Nacional foi o nosso referencial. O plano estadual, para a gente, não serviu de muita coisa, pois ele saiu depois que o nosso plano já estava praticamente pronto. Fizemos algumas adequações pequenas por conta do estadual, porém o nosso referencial maior foi o nacional. (Entrevistada 1, MB).

[...] na verdade, o plano foi feito com base no nacional, porque na verdade o estadual não estava pronto. Na verdade, não sei se já foi aprovado ou não, pois na época não estava. Então, o nosso PME foi alinhado com o nacional. (Entrevistada 1, MA).
}

Além do desafio de elaborar os Planos Municipais em um tempo restrito, os municípios enfrentaram dificuldades referentes à formação e à capacitação técnica dos gestores agravadas pela falta de clareza em torno dos objetivos que levou boa parte dos municípios pertencentes à região onde a pesquisa se desenvolveu à aprovação de metas e de estratégias idênticas às indicadas no documento nacional. Foram desconsideradas especificidades relacionadas ao contexto e às competências, conforme indicou a análise dos planos realizada na primeira etapa da pesquisa.

Como forma de subsidiar esse processo, a UNDIME mobilizou equipes para a realização de cursos de formação aos municípios que contaram com a presença de diversos agentes vinculados às Secretarias Municipais de Educação?. No caso dos municípios investigados, estabeleceu-se como critério de indicação para a participação nos referidos cursos, a "proximidade" e a "função" dos agentes no âmbito da administração da educação municipal que, conforme indicado pela própria UNDIME, assumiriam o papel de "multiplicadores" em seus territórios, auxiliando as equipes técnicas no processo de elaboração dos planos.

Apesar de importante do ponto de vista formativo, com oportunidades de reflexões e de troca de experiências entre os agentes participantes, as entrevistas revelaram que os cursos não foram suficientes para reduzir as dificuldades referentes à organização de um processo de maneira que ele refletisse um movimento democrático, com garantia de ampla participação social, conforme previsto nos subsídios oficiais.

\footnotetext{
${ }^{8}$ O Plano Estadual de Educação do Estado de São Paulo foi sancionado pela Lei Nº 16.279, de 8 de julho de 2016.

${ }^{9}$ Não foram obtidas informações concretas a respeito da quantidade de pessoas que participaram da formação da UNDIME de cada município.
} 
O tempo restrito destinado à elaboração dos planos somado à complexidade dos processos democráticos de tomada de decisão coletiva converteram-se em obstáculos para que a elaboração dos planos se constituísse em um rigoroso processo de análise conjunta sobre a realidade educacional dos municípios, tornando-se um instrumento efetivo de cidadania e de gestão que "[...] define a concepção e viabiliza a realização do projeto municipal de educação, superando rotinas, ações segmentadas e improvisações" (BORDIGNON, 2009, p. 92). Esses obstáculos fragilizaram o processo democrático de elaboração dos Planos Municipais, conforme relato da Entrevistada 1 MB:

Infelizmente, nós tivemos que elaborar o plano sem muito tempo para as pessoas dizerem o que pensavam sobre aquilo, pois nós tínhamos que entregar o plano até julho e tínhamos medo de alguma sanção acontecer caso não fosse entregue. Então, o tempo atrapalhou, acredito que, $90 \%$ do nosso trabalho. ${ }^{10}$ (Entrevistada 1, MB).

Outro fator considerado pelos entrevistados como elemento complicador do processo está relacionado ao já mencionado atraso na publicação do Plano Estadual de Educação do Estado de São Paulo. Ao tomar como referência as orientações dos órgãos oficiais, seja por meio dos cursos oferecidos pela UNDIME ou da leitura dos materiais de orientações publicados pelo Ministério da Educação, cujo conteúdo previa o envolvimento de todas as esferas governamentais para a elaboração de planos articulados, tendo em vista o atendimento das metas nacionais, os membros das equipes de elaboração locais avaliaram que seus planos não corresponderiam de forma integral aos pressupostos legais, apesar dos esforços empreendidos.

Essa "desarmonia" entre os entes federados, ao mesmo tempo que ampliou a dificuldade de consolidar as relações intergovernamentais, expandiu também as possibilidades de exercício da autonomia municipal, constantemente ameaçada pelos dispositivos de controle que acabam por gerar forte dependência dos municípios com relação às esferas estaduais e nacional. Apesar dessas orientações caminharem no sentido de oportunizar momentos de discussão e reflexão sobre as diretrizes municipais, os participantes foram acometidos por sentimentos de forte insegurança que podem indicar a falta de experiência dos agentes públicos frente a processos que não são mediados por princípios de subordinação e controle, como podemos observar no relato a seguir:

[...] faltou o direcionamento. O MEC, de certa forma, tinha no seu portal publicações, tinha essa orientação por parte do MEC. Mas, no Estado de São Paulo, a gente ficou esperando que o plano estadual saísse, que ele fosse construído. Então nós ficávamos assim, se precisamos ter como norte o Plano Estadual e Nacional, cadê o Estadual? (Entrevistada 2, MB).

O relato da Entrevistada 2/MB remete-nos a um importante princípio do Institucionalismo de não privilegiar a priori nenhuma determinação derivada do poder estatal, ou de qualquer outra instituição, como ação coercitiva por natureza. Antes, é preciso compreender que, por parte dos sujeitos, pode existir o desejo de conduzir suas ações sob tutela de uma instância legitimadora, desde que compartilhem das mesmas convicções e interesses (BAREMBLITT, 1994). Nesse caso, evidenciou-se o impulso coletivo de atender integralmente as orientações oficiais, cujo conteúdo não manifestou incompatibilidade de concepções com relação ao conteúdo do plano local, e o interesse de comprovar a articulação entre as metas locais e nacionais necessária ao recebimento de recursos via Sistema Integrado de Monitoramento Execução e Controle do Ministério da Educação (SIMEC).

\footnotetext{
${ }^{10}$ Segundo consta em documentos disponibilizados para o estudo, a elaboração do PME do MB iniciou-se em fevereiro de 2014 e deveria ser entregue em julho do mesmo ano.
}

Práxis Educativa, Ponta Grossa, v. 15, e2013790, p. 1-19, 2020

Disponível em: <http://www.revistas2.uepg.br/index.php/praxiseducativa> 
As limitações apontadas geraram diversos desafios à elaboração dos PME que resultaram na fragmentação desse processo, reflexo do modelo racional-hierárquico-burocrático de gestão orientado para o cumprimento de tarefas impostas pelo poder central. No caso do Município A, os participantes relataram desconhecimento da totalidade do conteúdo do Plano Municipal, pois, no momento de sua elaboração, as metas do PNE foram dividas e distribuídas aos participantes para que, sob coordenação de um de seus membros, fossem coletados dados e promovidas discussões que dessem origem a um conjunto de estratégias a serem contempladas nas metas dos Planos Municipais. Dessa maneira, conforme relatos dos entrevistados, a maioria dos participantes não contribuiu integralmente com o processo, ficando explícito o desconhecimento das decisões que correspondiam às demais metas.

Foi assim, eu fiquei com a meta 2 e meta 3, outro coordenador ficou com a meta 6 e 7, que deveria efetivar na rede, e eu discuti com o meu grupo somente as minhas metas, então o meu grupo desconhece as outras metas que contemplaram dentro do plano. (Entrevistada 2, MA).

[...] nós tínhamos pouco tempo e tínhamos 20 metas. Então, nós agrupamos: tudo que era da Educação Infantil, tudo que era do Ensino Fundamental, tudo que era do Ensino Médio, tudo que era do estado, tudo que era da universidade e o que era financeiro. E, aí, deve ter dado uns sete grupos mais ou menos, e as pessoas que estavam dispostas a trabalhar foram agrupadas, elas foram entrando de acordo com a proximidade que elas trabalhavam e tinham mais afinidade e foram entrando nesses grupos. E, aí, esses grupos iam trabalhando, eles tinham outras reuniões [...]. (Entrevistada 1, MB).

A despeito dessa fragmentação, utilizada como estratégia para acelerar a elaboração e a aprovação dos Planos Municipais no tempo determinado, observou-se que, dentro de suas possibilidades, os municípios se mobilizaram a fim de realizar um processo participativo e democrático, conforme previam as orientações dos documentos que nortearam a elaboração dos planos. No caso do MB, após a elaboração das estratégias, realizaram-se "miniconferências" como forma de ampliar a participação social. Nos eventos, foi garantindo o poder de veto, de modo que as metas e as estratégias pudessem sofrer novas alterações antes de serem encaminhadas à Câmara Municipal. As entrevistas revelaram que as discussões foram intensas e contaram com respaldos jurídico e sindical. Durante as discussões, estiveram em pauta questões políticas e trabalhistas, tendo em vista a diferenciação entre algumas categorias profissionais, por exemplo, a diferença entre "professor" e "educador" da Educação Infantil deste município (MB) que, embora exerçam a mesma função, possuem significativa distinção salarial, dando origem a uma situação complexa que o município enfrenta há algum tempo e, naquele momento, foi retomada e colocada em pauta.

Aqui nós contamos com a orientação do promotor que, na ocasião, estava à frente da promotoria da infância e juventude [...]. Talvez facilitasse para nós, pois ele estava aqui, ele participou muito ativamente, e todas as dúvidas que a gente tinha íamos até ele. Mas, por exemplo, nosso sindicato, ele tem uma abrangência regional, nós representamos 18 (dezoito) municípios, nos demais não aconteceu dessa forma; alguns não fizeram de uma forma participativa, teve uma equipe que pensou e elaborou e depois expôs para as demais pessoas envolvidas com a educação municipal. Tỉnha município que não teve nenhuma participação, as pessoas ficaram conhecendo quando a lei foi sancionada, aprovada. (Entrevistada 2, MB).

As entrevistas revelaram maiores dificuldades do município de pequeno porte em relação ao município de grande porte na organização do processo. Embora a Constituição Federal delegue a todos os municípios autonomia para definir as normas de seus respectivos sistemas de ensino, obedecendo aos princípios constitucionais e às diretrizes nacionais, vimos que no MA foi mais expressiva a ausência de assistência formativa, jurídica e, sobretudo, financeira.

Práxis Educativa, Ponta Grossa, v. 15, e2013790, p. 1-19, 2020

Disponível em: <http://www.revistas2.uepg.br/index.php/praxiseducativa> 
Tendo em vista a evidência de despreparo, em decorrência da insuficiência de tempo e de formação, e as dificuldades de planejamento apresentadas em ambos os municípios, os avanços com relação ao fortalecimento dos princípios democráticos são inegáveis, dentre os quais o exercício de construção participativa do Plano Municipal, com clara intenção, por parte dos sujeitos, de que o plano representasse as aspirações da comunidade local.

Os avanços, contudo, não foram suficientes para minimizar algumas consequências desfavoráveis - identificadas tanto nas entrevistas quanto no estudo da redação final dos PME relacionadas à pressão sofrida pela equipe de gestão municipal, devido ao tempo restrito, que acabou sendo transferida aos demais participantes, resultando na elaboração de um documento com dados pouco consistentes que não expressam as características do município em sua totalidade.

[...] a ausência de dados para elaborar o plano, foi assustador! [...]. O diagnóstico não teve tempo suficiente para o elaborar, tivemos que preparar as metas e estratégias sem o diagnóstico. Fizemos o caminho inverso! No meu ponto de vista era primeiro a gente vê o diagnóstico que temos no município e, na área de financiamento, de gestão, então qual é a realidade das escolas da Educação Básica? Qual a realidade das escolas públicas de Educação Básica? Os dados das escolas municipais a gente tinha, mas estaduais a gente não tinha! Então a gente não conseguiu, ninguém no grupo que fazia parte da rede estadual de São Paulo. Então não tínhamos nenhuma informação da rede do estado. Queríamos saber um pouco mais sobre como é que funcionava a rede de educação infantil, a creche das instituições privadas, a gente não tinha onde buscar, onde coletar. [...] outra coisa que foi bem complicada foi a cultura das pessoas de que o plano era para as escolas públicas municipais, e de que o plano não era para o Município. [...]. Tivemos poucos representantes de outros segmentos (instituição privada, rede estadual). (Entrevistada 3, MB).

A análise da elaboração dos PME nos municípios investigados demonstrou a fragilidade das relações existentes entre os sistemas de ensino que acaba por reforçar as marcas hegemônicas da descontinuidade e da ausência de articulação e de colaboração entre os entes federados. $\mathrm{O}$ reconhecimento das limitações presentes no decurso da elaboração dos planos do âmbito nacional ao local não invalida a relevância de algumas ferramentas operativas utilizadas pelos municípios com o objetivo de materializar seus projetos educacionais. Os limites referentes à participação não resultaram diretamente das ações dos sujeitos, mas refletiram o modelo de gestão pública, ainda fortemente centralizado, pautado no lançamento de normativas que desconsideram as realidades locais.

Destacou-se, no processo, a participação dos representantes dos sindicatos nas discussões voltadas à elaboração do PME do Município B. A colaboração desses membros ganhou visibilidade pela experiência por eles adquiridas em processos de tomada de decisões coletivas que foram transferidas aos debates, reforçando o compromisso com princípios democráticos. O registro das entrevistas expôs a participação ativa dos sindicatos não somente no período de elaboração do PME do Município B, mas nas reuniões das CONAES, onde vários membros se fizeram presentes. Em uma das falas, a entrevistada destacou a participação sindical e denunciou a dificuldade dos municípios na elaboração dos planos, que acabou sendo sanada pela via da não-participação:

Nosso sindicato tem uma abrangência regional. Nós representamos 18 municípios, nos demais não aconteceu dessa forma. Alguns municípios não fizeram de uma forma participativa, teve uma equipe que pensou e elaborou e depois expôs para as demais pessoas envolvidas com a educação do município. Teve município que não teve nenhuma participação, as pessoas ficaram conhecendo quando a lei foi sancionada, aprovada. Alguns municípios pediram orientação, pois, anteriormente à construção do plano, nós fizemos um debate, trouxemos uma professora da Universidade Federal de Dourados,

Práxis Educativa, Ponta Grossa, v. 15, e2013790, p. 1-19, 2020 Disponível em: <http://www.revistas2.uepg.br/index.php/praxiseducativa $>$ 
também trouxemos um deputado; então nós fizemos essa discussão anterior. (Entrevistada 2, MB).

Constatou-se a expressividade da experiência democrática na atuação dos membros dos sindicatos que atuaram no sentido de reforçar o processo de decisão coletiva, resistindo à redução desses espaços em instâncias burocráticas de cumprimento de ordens emanadas do poder central. Todavia, a entrevistada ressaltou que a qualidade do processo democrático depende da ampliação dos espaços de discussões, que é um grande desafio a ser superado.

\begin{abstract}
Algo que eu sinto que faltou é irmos com as discussões nas periferias, nas escolas das periferias, então acho que talvez eu fosse dar uma sugestão agora, é para que essas audiências também aconteçam nesses espaços, tanto em escolas municipais como estaduais, pois são pontos estratégicos. Fazer uma reunião em cada região da cidade, porque, aí, nós teríamos a participação lá, da sociedade local. Pois percebíamos que a participação maior era dos profissionais, dos sindicatos, das universidades. (Entrevistada 2, MB).
\end{abstract}

Conforme orientações externas apresentadas em diversos subsídios produzidos pelo Governo Federal ${ }^{11}$, o Município B organizou Fóruns Municipais de Educação para discutir e monitorar o Plano Municipal. Nos Fóruns, estiveram presentes representantes de vários segmentos: psicólogos, fonoaudiólogos, representantes das universidades e da Secretária Municipal de Educação. Esse movimento não foi identificado no Município A, embora, nesse município, a participação tenha sido significativa, refletindo-se na redação do documento que demonstrou significativo alinhamento às demandas locais.

Nas entrevistas, identificou-se a falta de perspectiva no que diz respeito à efetivação das propostas do plano, especialmente devido a impasses de ordem político-administrativa, como a rotatividade da equipe gestora, cujos cargos são comissionados e não concursados, que impedem conhecimento amplo do contexto que envolvem questões financeiras. Conforme se notou em uma das falas, o caráter burocrático do processo foi outro obstáculo presente na elaboração:

[...] tem coisas que já tinham que estar sendo providenciadas. A questão financeira, por exemplo. A revisão do plano de carreira era uma das coisas que estava lá (PNE) e também estão no nosso plano alguns itens que não batem com o plano municipal, e terão que ser revistos porque nós não vamos ter condições financeiras para fazer aquilo. Questão salarial, questão de igualdade do salário, acho meio difícil de acontecer! Então eu acho que algumas coisas não vão acontecer por conta do planejamento, outras não vão acontecer por falta de condições que o governo não deu respaldo, colocou no plano, mas o município não tem respaldo, principalmente as condições financeiras. Aliás, ao contrário, vem diminuindo a arrecadação, diminuindo o repasse. Então algumas coisas não vão acontecer por questão de planejamento mesmo, e algumas vão acontecer por que vai acontecer [risos]. (Entrevistada 1, MA).

A consonância entre o conteúdo dos Planos Municipais e Estaduais com o Plano Nacional, considerada fundamental à efetivação do regime de colaboração e, consequentemente, da consolidação do Sistema Nacional de Educação, somente poderia ter sido integralmente respeitada se houvesse garantias efetivas de repasses de recursos suficientes à efetivação das metas. Não havendo essa garantia fundamental, certo grau de autonomia tornou-se necessário para que os sujeitos delineassem regras próprias em atendimento às suas particularidades e aos seus limites orçamentários.

11 A respeito das orientações voltadas à composição dos Fóruns Municipais de Educação, consultar <http://fne.mec.gov.br/images/Biblioteca/MateriasdeDivulgacaoFME/FolderFMEA3.pdf>. Acesso em: 16 out. 2018.

Práxis Educativa, Ponta Grossa, v. 15, e2013790, p. 1-19, 2020

Disponível em: <http://www.revistas2.uepg.br/index.php/praxiseducativa> 
Os entrevistados de ambos os municípios declararam a existência de certa autonomia na elaboração dos planos; todavia, o conteúdo das entrevistas revelou a falta de clareza com relação ao referido conceito, conforme é possível observar no seguinte excerto:

\begin{abstract}
Tivemos total autonomia, total! Se você for falar no sindicato, eles vão dizer outra coisa que não tinham autonomia, porque tinha uma pessoa lá, que ficava falando que não havia dinheiro para tudo isso. Porque o sindicato tem essa impressão. De fato, não estamos conseguindo cumprir nem as metas básicas, que é criação de cargo de professor para substituir, isso é básico, não estou conseguindo cumprir. (Entrevistada 4, MB).
\end{abstract}

A autonomia assumiu, nesse caso, um aspecto superficial, convertendo-se em uma estreita margem de liberdade para que os agentes adequassem suas políticas locais aos limites impostos em âmbito Federal. Notou-se que a preocupação fundamental se dirigiu ao cumprimento da "tarefa" a eles delegada referente à elaboração do plano no tempo determinado em lei. Cumprida a tarefa, os agentes com maior poder de decisão encontraram formas de interferir no conteúdo do plano, retirando metas e estratégias que não poderiam ser assumidas devido à possibilidade de comprometimento dos recursos financeiros disponíveis.

A gente digitava tudo o que foi resolvido e cada responsável pela sala da meta é que
passava para o pessoal o que tinha sido decidido. Eu não acho muito legal falar isso, mas,
algumas coisas que ali foram decididas não foram anexadas, pois iriam causar problema
financeiro para o município. Bem, isso eu sei, pois estava no grupo, mas as pessoas que
estavam fora, elas nem sabem disso. Tivemos algumas ideias que colocamos nesse plano
em colaboração com a comunidade, mas que elas simplesmente sumiram. Eles só
deixaram, na verdade, o que era obrigatório. E isso não aparece, não é conversado. Então
só existe a lei, o que tem que se cumprir. (Entrevistada 2, MA).

O atendimento das orientações oficiais, no que diz respeito à organização de processos democráticos de decisão, foi realizado em meio a alguns limites constituídos por diversos fatores, com destaque aos orçamentários. A esse respeito, manifestou-se uma das entrevistadas:

[...] nós tivemos uma linha de pensamento muito real quando organizamos essas metas, nós sonhamos sim, mas não sonhamos desmedidamente, a gente pensou no hoje, no amanhã, nos prazos. Todas as metas do PME estão no Plano de Ações Articuladas (PAR), a gente já fez o diagnóstico da rede toda para a construção do nosso plano de gestão estratégica, para o plano municipal. A gente tem os promotores, tanto o ministério público como o tribunal de contas, analisando as coisas que o município faz com relação ao Plano Municipal de Educação. Então nós temos uma cobrança intensiva nisso, e nós temos aqui, dentro da Secretaria de Educação, tanto a secretária como as coordenadorias pensando nessas metas do plano. Então todo o nosso planejamento para esse ano e para os próximos anos é com base no Plano Municipal de Educação. (Entrevistada 5, MB).

Conforme ilustra o excerto, no contexto de elaboração do Plano Municipal, o PAR atuou como instrumento de gestão e de planejamento nas esferas subnacionais. Ao exigir o alinhamento dos Planos Municipais ao Plano Nacional e convertê-los em condição à garantia de recebimento de assistência técnica e financeira, o Governo Federal ampliou as possibilidades de exercício de um tipo de "autonomia regulada", em que os sujeitos se articulam com base em orientações delineadas externamente, garantindo a legitimidade do processo, ao mesmo tempo que adotam estratégias internas, como as significativas alterações arbitrárias na redação do documento municipal voltadas ao atendimento de interesses políticos que variam de acordo com os diferentes contextos.

Os aspectos teóricos, políticos, administrativos e funcionais que orientaram o trabalho das equipes gestoras nos municípios investigados se assentaram em uma perspectiva democrática, conforme proposto nos materiais de orientações, demonstrando a influência dos agentes governamentais nas esferas locais. O entendimento da política educacional como processo flexível e não determinado, permitiu-nos observar que as ações colaborativas e consensuais, possibilitadas

Práxis Educativa, Ponta Grossa, v. 15, e2013790, p. 1-19, 2020

Disponível em: <http://www.revistas2.uepg.br/index.php/praxiseducativa> 
pela adoção de práticas administrativas participativas, ocorreram juntamente a mecanismos de controle e de subordinação aos ditames institucionais nacionais e das próprias secretarias municipais.

As constatações da pesquisa permitem-nos considerar que o poder instituído induz práticas capazes de reforçar novos modos de se fazer política - como foi o caso das orientações para a elaboração dos Planos Municipais, em que se valorizaram processos de tomada de decisões coletivos, ancorados, portanto, em pressupostos democráticos -, assim como fortalecer o uso de estratégias que reforçam o centralismo histórico no campo da política educacional que fragilizam a autonomia municipal indispensável ao fortalecimento das relações democráticas dos sistemas locais. Nas conclusões deste artigo, retomaremos, brevemente, alguns pressupostos do referencial teórico apresentados, articulando-os aos principais achados da pesquisa.

\section{Conclusão}

As entrevistas realizadas com os sujeitos que participaram do processo de elaboração dos Planos Municipais de Educação de dois municípios do interior paulista revelaram práticas que dão visibilidade à forte tensão existente entre os planos instituído e instituinte, cujo resultado é uma dinâmica de execução das orientações oficiais mediada por fortes relações de interesses divergentes entre si que resultam no impedimento da materialização da política tal como projetada no contexto de elaboração do texto legal. Observou-se que, embora as orientações oficiais tenham influenciado as decisões dos participantes, servindo como principal referência na organização do processo, as demandas locais foram determinantes na aprovação das metas dos planos, tendo em vista as requisições dos gestores municipais, referentes, sobremaneira, a questões orçamentárias.

Ao articularmos o macro e o micro contexto na apresentação dos dados, procuramos enfatizar a ação dos sujeitos sem minimizar o impacto da ação estatal sobre os processos de tomada de decisões, conferindo visibilidade ao plano instituinte, em que as decisões ocorrem em meio a conflitos e a conformismos, a subterfúgios e a acomodações, tal como Mainardes (2006) nos chama atenção ao apresentar os pressupostos dos estudos baseados na abordagem do Ciclo de políticas. Os processos de resistência expressaram-se fortemente no esforço empreendido por agentes envolvidos na elaboração dos planos nos dois municípios de conduzir o processo democraticamente, garantindo a participação de representantes da comunidade escolar, dos movimentos civis e demais membros dos conselhos municipais nos debates promovidos em eventos e nos fóruns municipais. Mesmo diante da imposta restrição de tempo e de ausência de orientações mais precisas por parte dos órgãos centrais, os espaços foram utilizados estrategicamente pelos agentes locais, conferindo maior legitimidade às decisões que, em ambos os municípios, respeitaram as particularidades regionais sem deixar de atender às prerrogativas nacionais.

Importa ressaltarmos que o cumprimento das exigências externas não se deu com base em um compromisso coletivo firmado nacionalmente com vistas à consolidação do Sistema Nacional de Educação, conforme previsto nos documentos que nortearam a elaboração do Plano Nacional de Educação (2014-2024), mas com claro interesse dos sistemas municipais de cumprir com a agenda imposta pelo Ministério da Educação por meio da vinculação do repasse de recursos à aprovação dos Planos Municipais, cujo controle se deu por meio de um sistema digital integrado criado com o objetivo de coordenar a execução do Plano de Ações Articuladas (PAR).

$\mathrm{Na}$ ausência de políticas de financiamento mais efetivas com vistas à ampliação dos recursos para o cumprimento do Plano Nacional de Educação, o Estado brasileiro lançou mão de sistemas de controle da qualidade na oferta do ensino consolidados em sistemas avaliativos e de 
monitoramento que se converteram em práticas de responsabilização compartilhada e de autocontrole. Simultaneamente e de forma articulada, os sujeitos desenvolveram estratégias, produziram saberes próprios, construíram dispositivos alinhados com suas demandas e, com a ajuda de "experts aliados" - como foi o caso do MB que contou com o apoio de um promotor de justiça - buscaram saídas que possibilitaram o cumprimento da agenda imposta pelo poder instituído sem comprometer a dinâmica organizativa dos sistemas locais (BAREMBLITT, 1994).

O processo descrito e analisado refletiu um tipo de autogestão inserido em um plano instituinte, de autoanálise, de produção de novos saberes que não poderiam ter sido produzidos de antemão, pois resultaram da experiência que é sempre particular, provisória e irreprisável. Ainda que fossem identificadas hierarquias e processos organizativos conduzidos de forma arbitrária conforme demonstrados nas entrevistas que relataram os trabalhos de formação oferecidos pela UNDIME e coordenados por membros da Secretaria Municipal -, evidenciou-se um "[...] saber coletivo produzido, distribuído e exercitado na vida coletiva”. Nas palavras de Baremblitt (1994):

\footnotetext{
$\mathrm{Na}$ topografia deste saber existem alguns campos, alguns elementos que são os essenciais e que são compartilhados por todo mundo. Então, quando esse saber compartilhado é delegado a alguns que se especializam nessa questão, já não é um saber produzido fora dos interesses do coletivo, já não é um saber que vai cair de cima para baixo, de fora para dentro. É já uma delegação, porque foi produzido de dentro, por alguns especialistas do assunto em estreita colaboração com os diretamente interessados nos benefícios que esse saber e suas aplicações terão, uma vez realizados. (BAREMBLITT, 1994, p. 20).
}

A análise do contexto de elaboração dos planos nos municípios demonstrou a impossibilidade de analisar os contextos que compõem o Ciclo de políticas isoladamente. A análise do contexto de elaboração do texto da política - nesse caso, os Planos Municipais de Educação refletiu-se como um contexto prático, com processos de resistência e conformismos, mas também de produção de saberes instituintes que refletem "resultados e efeitos" produzidos em um complexo "contexto de estratégias políticas" que podem contribuir com o debate da política investigada assim como o redimensionamento dessa política em outros espaços (MAINARDES, 2006, p. 68).

Concluímos que, em um momento de fortes ataques à democracia, realizar pesquisas que confiram visibilidade às práticas institucionais é fundamental não apenas para reforçar as lutas voltadas à manutenção dos espaços coletivos de tomada de decisões conquistados nas últimas décadas, mas para nos lembrar que, a despeito das ações cada vez mais repressivas do Estado regulador, a potência da Ação Política como processo criativo e transformador se mantém pulsante e talvez tenha sido essa a maior contribuição do amplo debate que se promoveu em torno da elaboração dos Planos Municipais de Educação, cuja execução - temporariamente inviabilizada pelo descaso do atual Governo brasileiro - convoca-nos à permanente mobilização.

\section{Referências}

ARANDA, M. A. M.; PERBONI, F.; RODRIGUES, E. S. O Plano Municipal de Educação de Dourados - MS: política, gestão e participação. Diálogo Educacional, Curitiba, v. 18, n. 57, p. 416-436, abr./jun. 2018. DOI: http://dx.doi.org/10.7213/1981-416X.18.057.DS06

AVELAR, M. Entrevista com Stephen J. Ball: uma análise de sua contribuição para a pesquisa em política educacional. Archivos Analíticos de Políticas Educativas, v. 24, n. 24, p. 1-18, 2016. DOI: https://doi.org/10.14507/epaa.24.2368

BARDIN, L. Análise de conteúdo. 4. ed. Lisboa: Edições 70, 2009. 
BAREMBLITT, G. Compêndio de análise institucional e outras correntes. 2. ed. Rio de Janeiro: Rosa dos Tempos, 1994.

BRASIL. Lei No 10.172, de 9 de janeiro de 2001. Aprova o Plano Nacional de Educação e dá outras providências. Diário Oficial da União: seção 1, Brasília, DF, n. 7, p. 1-20, 10 jan. 2001.

BRASIL. Lei No 13.005, de 25 de junho de 2014. Aprova o Plano Nacional de Educação - PNE e dá outras providências. Diário Oficial da União: seção 1, Brasília, DF, n. 120-A, edição extra, p. 1-7, 26 jun. 2014.

BORDIGNON, Genuíno. Gestão da educação no município: sistema, conselho e plano. São Paulo: Editora e Livraria Instituto Paulo Freire, 2009. (Educação Cidadã; 3).

DOURADO, L. F. A Conferência Nacional de Educação, o Plano Nacional e a construção do Sistema Nacional de Educação. Revista Brasileira de Política e Administração da Educação, v. 25 , n. 2, p. 365-376, 2009.

FOUCAULT, M. Microfísica do poder. Rio de Janeiro: Edições Graal, 1979.

HARVEY, D. A condição pós-moderna. São Paulo: Atlas, 1989.

HOJAS, V. F. Pesquisar escolas: "abordagem do ciclo de políticas" e "teoria da atuação política" em discussão. Contrapontos, Itajaí, v. 19, n. 1, p. 301-313, 2019. DOI: http://dx.doi.org/10.14210/contrapontos.v19n1.p301-313

HOSTINS, R. C. L.; ROCHADEL, O. Contribuições de Stephen Ball para o campo das políticas educacionais. Revista on line de Política e Gestão Educacional, Araraquara, v. 23, n. 1, p. 61 84, jan./abr. 2019. DOI: https://doi.org/10.22633/rpge.v23i1.11947

LAPASSADE, G. Da multirreferencialidade como "bricolagem”. In: BARBOSA, J. G. (Coord.). Multirreferencialidade nas ciências e na educação. São Carlos: Editora da UFSCar, 1998. p. 24-41.

LIMA, L. C. A escola como organização educativa: uma abordagem sociológica. São Paulo: Cortez, 2001.

LIMA, L. F.; SOUZA, B. S.; LUCE, M. B. A abordagem do ciclo de políticas nos Programas de Pós-Graduação brasileiros: um mapa das teses e dissertações. Revista de Estudios Teóricos y Epistemológicos en Política Educativa, Ponta Grossa, v. 3, p. 1-29, 2018. DOI: https://doi.org/10.5212/retepe.v.3.008

MAINARDES, J. Abordagem do ciclo de políticas: uma contribuição para a análise de políticas educacionais. Educação \& Sociedade, Campinas, v. 27, n. 94, p. 47-69, jan./abr. 2006.

MAINARDES, J. A abordagem do ciclo de políticas: explorando alguns desafios da sua utilização no campo da Política Educacional. Jornal de Políticas Educacionais, Curitiba, v. 12, n. 16, p. 1 19, 2018. DOI: $\underline{\text { http://dx.doi.org/10.5380/jpe.v12i0.59217 }}$

MAINARDES, J.; GANDIN, L. A. A abordagem do ciclo de políticas como epistemetodologia: usos no Brasil e contribuições para a pesquisa sobre políticas educacionais. In: TELLO, C.; ALMEIDA, M. L. P. (Orgs.). Estudos epistemológicos no campo da pesquisa em Política Educacional. Campinas: Mercado de Letras, 2013a. p. 143-167. 
MAINARDES, J.; GANDIN, L. A. Contributions of Stephen J. Ball to the research on educational and curriculum policies in Brazil. London Review of Education, v. 11, n. 3, p. 256-264, nov. 2013b. DOI: https://doi.org/10.1080/14748460.2013.840985

MAINARDES, J.; MARCONDES, M. I. Entrevista com Stephen J. Ball: um diálogo sobre justiça social, pesquisa e política educacional. Educação \& Sociedade, Campinas, v. 30, n. 106, p. 303318, jan./abr. 2009. DOI: https://doi.org/10.1590/s0101-73302009000100015

MAINARDES, J.; STREMEL, S. Informações sobre a abordagem do ciclo de políticas. Ponta Grossa: UEPG, $2015 . \quad$ Disponível em: <https://www.researchgate.net/profile/Jefferson_Mainardes/publications>. Acesso em: 14 mar. 2020 .

PAVEZI, M. Contribuições da teoria da atuação: análise a partir de uma pesquisa sobre políticas de Educação Especial no contexto da prática. Revista de Estudios Teóricos y Epistemológicos en Política Educativa, Ponta Grossa, v. 3, p. 1-19, 2018. DOI: https://doi.org/10.5212/retepe.v.3.009

ROSA, S. S. da. Uma introdução às ideias e às contribuições de Stephen J. Ball para o tema da implementação de políticas educacionais. Revista de Estudios Teóricos y Epistemológicos en Política Educativa, Ponta Grossa, v. 4, p. 1-17, 2019. DOI: https://10.5212/retepe.v.4.004

SOUSA, M. Apontamentos teórico-metodológicos: contribuições de Stephen J. Ball para as pesquisas de políticas educacionais. Revista de Estudios Teóricos y Epistemológicos en Política Educativa, Ponta Grossa, v. 3, p. 1-22, 2018. DOI: https://doi.org/10.5212/retepe.v.3.016

VIEIRA, S. L. Planos e políticas educacionais: das concepções às práticas. In: SOUZA, D. B.; MARTINS, A. M. (Orgs.). Planos de educação no Brasil: planejamento, políticas, práticas. São Paulo: Edições Loyola, 2014. p. 55-71.

Recebido em 16/08/2019

Versão corrigida recebida em 14/03/2020

Aceito em 16/03/2020

Publicado online em 27/03/2020

Práxis Educativa, Ponta Grossa, v. 15, e2013790, p. 1-19, 2020 